\title{
Quality Assessment for Delta and Theta Binaural Beats
}

\author{
Fatin E.M. Al-Obaidi and Ali Jassim Mohamed Ali \\ Department of Physics, College of Science, Mustansiriyah University, Baghdad, Iraq
}

\begin{abstract}
Due to brain's internal wiring, a beating effect will be created in it as soon as two sine waves with slightly different frequencies be applied to each ear. Brain's response to such beat remains controversial; therefore and in addition to author's desire toward investigate the role of beat and carrier frequencies upon the brain, this research introduces a new way for quantifying such phenomenon by using an objective methods of quality assessment. In such method, the criteria of error visibility (differences) between tones had been tested. Delta and Theta waves had been used here to investigate their beat and carrier frequencies inside the brain. Results show a similarity behavior for both Delta and Theta waves. Delta wave appeared to be better effect than Theta due to its highest structural dissimilarity metric (DSSIM) which indicates a greater similarity between tones than Theta wave.
\end{abstract}

Key words: Binaural beat, Structural Similarity Index Metric (SSIM), Structural Dissimilarity Metric (DSSIM), beat frequency, carrier frequency

\section{INTRODUCTION}

The dichotic presentation of two nearly equivalent pure tones with slightly different frequencies lead to what we called 'beat' in the brain. The beat in this case generated within the brain and is referred to as a 'binaural beat' (Jirakittayakorn and Wongsawat, 2017; Chaieb et al., 2015). When a tone of $410 \mathrm{~Hz}$ presented to the right ear as an example and a $420 \mathrm{~Hz}$ one to the left, then a beat of 10 $\mathrm{Hz}$ shall be perceived and located in the brain with carrier frequency of $415 \mathrm{~Hz}$ (Chaieb et al., 2015; Anonymous, 2017). In general, binaural beat can occurred if the carrier frequency of the left and right stimulus is no longer than $1500 \mathrm{~Hz}$ with a difference of the two tones which not exceed $50 \mathrm{~Hz}$ (Mihajloski et al., 2014; Anonymous, 1997). In 1839, H.W. Dove discovered the concept of binaural beat and then outlined with more details by G. Oster over five decades ago (Kneidinger, 2015; Padmanabhan et al., 2005). The researchers by Padmanabhan et al. (2005) found that binaural beat audio has the role in decreasing acute pre-operative anxiety affectively. For inducing a meditative state, Jirakittayakorn and Wongsawat (2017) suggested that $6 \mathrm{~Hz}$ binaural beat on a $250 \mathrm{~Hz}$ carrier tone can be regard as a good stimulus. Mihajloski et al. (2014) developed a new procedure of evoking transient auditory evoked potentials to binaural beats by adopting frequency modulated stimuli. Table 1 summarizes brain wave with its four bands.

An attempt to visualize delta and theta brain waves has been chosen to test by utilizing quality assessment. The latter is a crucial need which is closely related to signal differences assessment in which quality

\begin{tabular}{ll} 
Table 1: Brain waves types (Anonymous, 2017) & \\
\hline Brain wave & Frequency range $(\mathrm{Hz})$ \\
\hline Delta & $0.5-4$ \\
Theta & $4-7.5$ \\
Alpha & $7.5-14$ \\
Beta & $14-40$ \\
Gamma & $>40$ \\
\hline
\end{tabular}

is based on the differences between left and right tones (Al-Obaidi, 2017; Varnan et al., 2011). Due to certain considerations related to its cost, an objective method is seems to be more preferable than the subjective one in the quality process (George and Prabavathy, 2014).

\section{MATERIALS AND METHODS}

$$
\begin{aligned}
& \text { Objective quality assessment } \\
& \text { Human Visual System (HVS) feature based metrics } \\
& \text { Structural Similarity Index Metric (SSIM): This measu } \\
& \text { compares two signals using information about } \\
& \text { luminous, contrast and structure as follow (Al-Obaid, } \\
& \text { 2017; Varnan et al., 2011): } \\
& \qquad 1(\mathrm{x}, \mathrm{y})=\frac{2 \mu_{\mathrm{x}}(\mathrm{x}, \mathrm{y}) \mu_{\mathrm{y}}(\mathrm{x}, \mathrm{y})+\mathrm{C}_{1}}{\mu_{\mathrm{x}}^{2}(\mathrm{x}, \mathrm{y})+\mu_{\mathrm{y}}^{2}+\mathrm{C}_{1}} \\
& \qquad \mathrm{C}(\mathrm{x}, \mathrm{y})=\frac{2 \sigma_{\mathrm{x}}(\mathrm{x}, \mathrm{y}) \sigma_{\mathrm{y}}(\mathrm{x}, \mathrm{y})+\mathrm{C}_{2}}{\sigma_{\mathrm{x}}^{2}(\mathrm{x}, \mathrm{y})+\sigma_{\mathrm{y}}^{2}(\mathrm{x}, \mathrm{y})+\mathrm{C}_{2}} \\
& \mathrm{~S}(\mathrm{x}, \mathrm{y})=\frac{\sigma_{\mathrm{xy}}(\mathrm{x}, \mathrm{y})+\mathrm{C}_{3}}{\sigma_{\mathrm{x}}(\mathrm{x}, \mathrm{y}) \sigma_{\mathrm{y}}(\mathrm{x}, \mathrm{y})+\mathrm{C}_{3}}
\end{aligned}
$$$$
\text { Structural Similarity Index Metric (SSIM): This measure }
$$$$
\text { compares two signals using information about }
$$$$
\text { luminous, contrast and structure as follow (Al-Obaidi, }
$$

Corresponding Author: Fatin E.M. Al-Obaidi, Department of Physics, College of Science, Mustansiriyah University, Baghdad, Iraq 
Where:

$\mathrm{x}$ and $\mathrm{y}=$ Two different positions in two separate signals

$F_{x}$ and $F_{x y}=$ Are the average of $x$

standard deviation of $x$ and the covariance of $\mathrm{x}$ and $\mathrm{y}$, respectively where (Al-Dalawy, 2013):

$$
\begin{aligned}
& \mu_{\mathrm{x}}(\mathrm{x}, \mathrm{y})=\sum_{\mathrm{p}=-\mathrm{P}}^{\mathrm{P}} \sum_{\mathrm{q}=-\mathrm{Q}}^{\mathrm{Q}} \mathrm{w}(\mathrm{p}, \mathrm{q}) \mathrm{x}(\mathrm{x}+\mathrm{p}, \mathrm{y}+\mathrm{q}) \\
& \sigma_{\mathrm{x}}^{2}(\mathrm{x}, \mathrm{y})=\sum_{\mathrm{p}=-\mathrm{P}}^{\mathrm{P}} \sum_{\mathrm{q}=-\mathrm{Q}}^{\mathrm{Q}} \mathrm{w}(\mathrm{p}, \mathrm{q}) \\
& {\left[x(x+p, y+q)-\mu_{x}(x, y)\right]^{2}}
\end{aligned}
$$

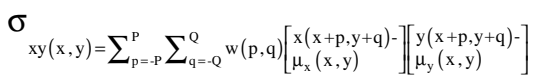

where, w (p, q) is a Gaussian weighting function such that:

$$
\sum_{\mathrm{P}=-\mathrm{P}}^{\mathrm{P}} \sum_{\mathrm{q}=-\mathrm{Q}}^{\mathrm{Q}} \mathrm{w}(\mathrm{p}, \mathrm{q})=1
$$

And $\mathrm{C}_{1}, \mathrm{C}_{2}$ and $\mathrm{C}_{3}$ are constants given by Al-Dalawy (2013), Wang and Li (2011):

$$
\begin{aligned}
& \mathrm{C}_{1}=\left(\mathrm{K}_{1} \mathrm{~L}\right)^{2} \\
& \mathrm{C}_{2}=\left(\mathrm{K}_{2} \mathrm{~L}\right)^{2}
\end{aligned}
$$
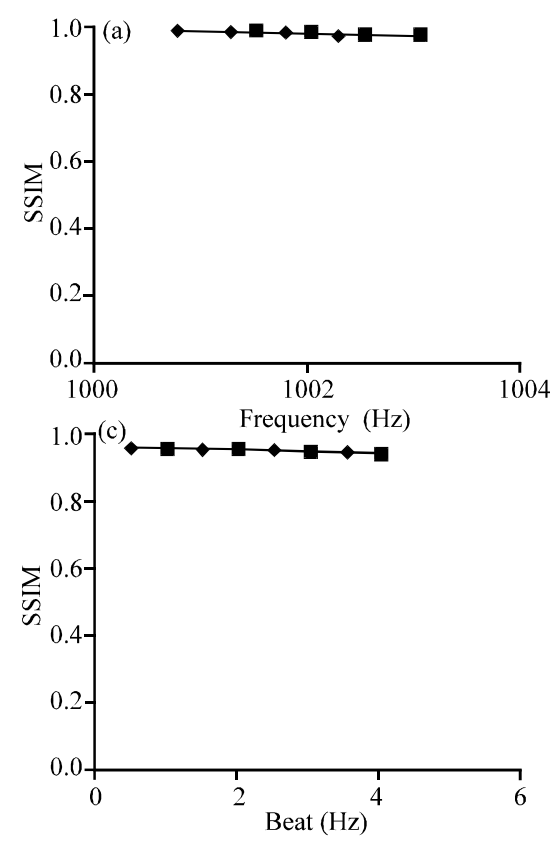

$$
\mathrm{C}_{3}=\mathrm{C}_{2} / 2
$$

$\mathrm{L}$ is the dynamic range for the sample data and $\mathrm{K}_{1}+\mathrm{H}$ and $\mathrm{K}_{2}+\#$ are two scalar constants. Throughout this research a value of 0.01 and 0.03 are set to parameter $K_{1}$ and $\mathrm{K}_{2}$ respectively (Al-Dalawy, 2013). The structure similarity can be written as (Wang and Li, 2011):

$$
\operatorname{SSIM}(x, y)=[1(x, y)] \cdot[c(x, y)] \cdot[s(x, y)]
$$

SSIM is a decimal value between $(-1,1)$ (Nisha and Kumar, 2013).

DSSIM: This is the structural dissimilarity metric which is derived from SSIM as follows (Nisha and Kumar, 2013):

$$
\operatorname{DSSIM}(x, y)=\frac{1}{1-\operatorname{SSIM}(x, y)}
$$

The greater values of SSIM and DSSIM refer to greater similarity between signals (Varnan et al., 2011).

\section{RESULTS AND DISCUSSION}

In this research, Delta and Theta sine tones had been adopted through the web site found by Anonymous, (2017). A general preview for the used tones can be

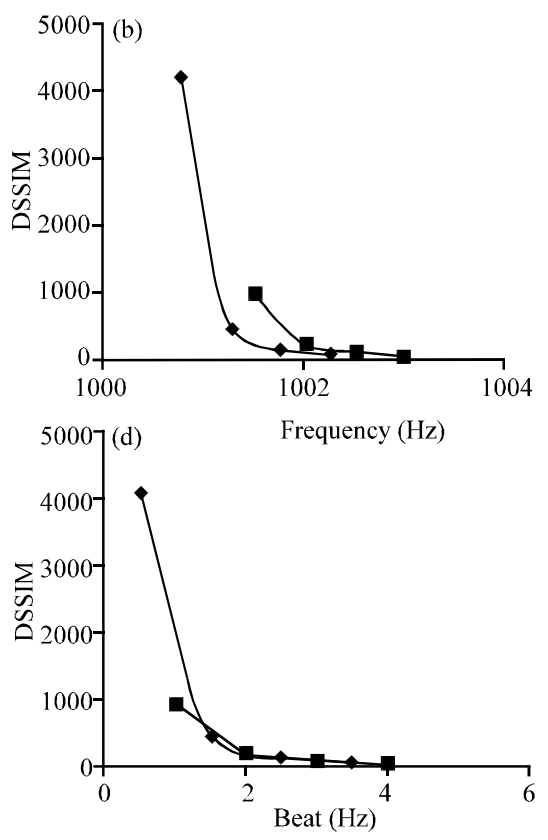

Fig. 1: a- d) Delta brain wave relationships with carrier and beat frequencies; Blue series for range (1000.75-1002.25) and Red series for range (1001.5-1003) 

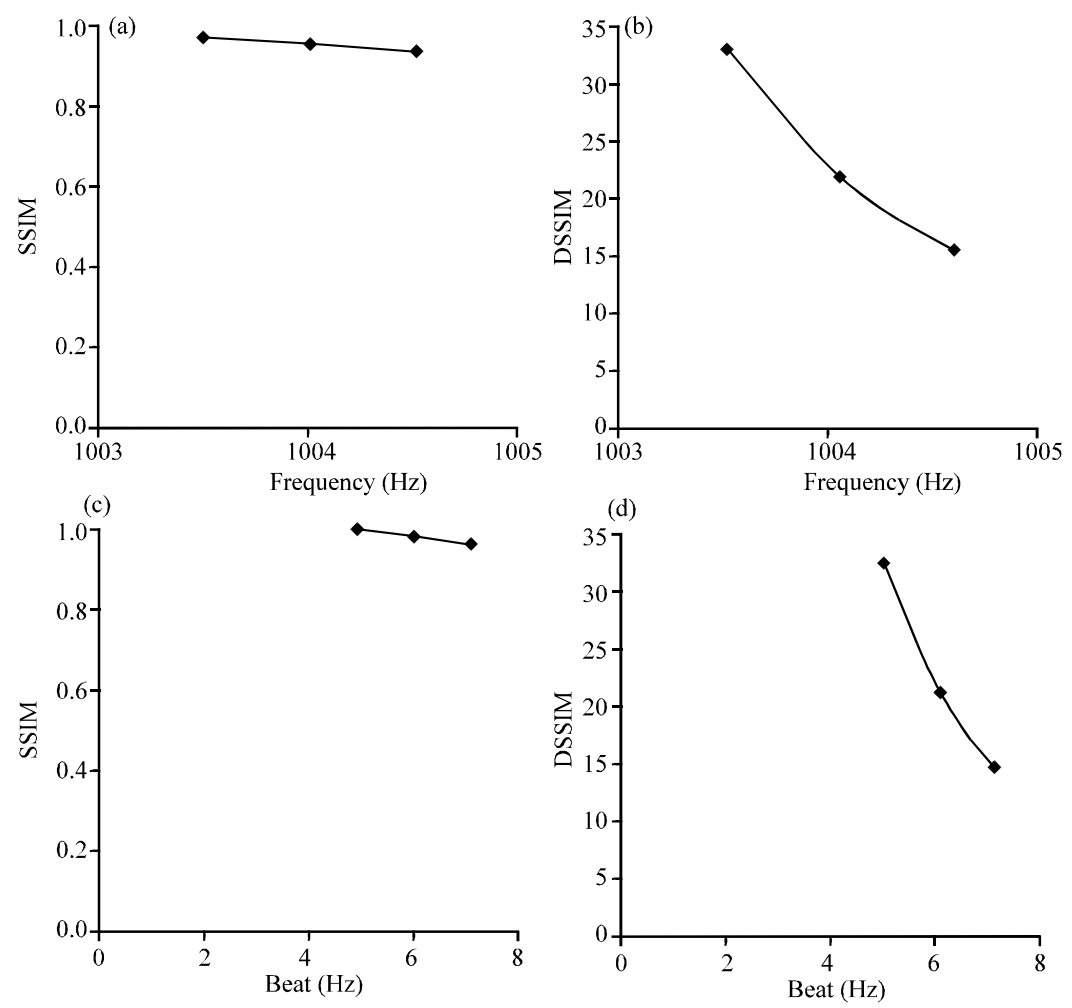

Fig. 2: a-d) Theta brain wave relationships with carrier and beat frequencies; Blue series for range (1003.5-1004.5)

\begin{tabular}{|c|c|c|c|c|}
\hline Brain wave & 1st wave & 2nd wave & Carrier frequency & Beat frequency \\
\hline \multirow[t]{8}{*}{ Delta } & 1001.0 & 1002 & 1001.50 & 1.0 \\
\hline & & 1003 & 1002.00 & 2.0 \\
\hline & & 1004 & 1002.50 & 3.0 \\
\hline & & 1005 & 1003.00 & 4.0 \\
\hline & 1000.5 & 1001 & 1000.75 & 0.5 \\
\hline & & 1002 & 1001.25 & 1.5 \\
\hline & & 1003 & 1001.75 & 2.5 \\
\hline & & 1004 & 1002.25 & 3.5 \\
\hline \multirow[t]{3}{*}{ Theta } & 1001.0 & 1006 & 1003.50 & 5.0 \\
\hline & & 1007 & 1004.00 & 6.0 \\
\hline & & 1008 & 1004.50 & 7.0 \\
\hline
\end{tabular}

summarized in Table 2. Figure 1 and 2 show SSIM and DSSIM relationships with beat and carrier frequencies, respectively.

Results show a similarity behavior for both Delta and Theta waves. A descent state appeared for DSSIM relations with increasing carrier and beat frequencies respectively while a nearly straight decreased one occurred in the case of SSIM relationships with increasing carrier and beat frequencies, respectively. In each used brain wave, the lower end seem to be the best one to handle. DSSIM measure is much better in detecting the similarity between signals than SSIM.

\section{CONCLUSION}

A binaural beat is a beat phenomenon generated by dichotic presentation of two nearly equivalent pure tones with slightly significant different frequencies. Among the used Delta and Theta waves, one can noticed the similarity behavior for the two brain waves with increasing the carrier and beat frequencies. According to results, Delta wave appeared to be better effect than Theta due to its highest DSSIM values which indicates a greater similarity between signals than Theta wave.

\section{REFERENCES}

Al-Dalawy, N.M.M., 2013. Optical image analysis for the underwater targets. Ph.D Thesis, Department of Physics, College of Science, Al-Mustansiriyah University,Baghdad, Iraq.

Al-Obaidi, F.E.M., 2017. Spectral analysis for polychromatic light sources and drinking water samples by using blind quality assessment. J. Kufa Math. Comput., 4: 8-12.

Anonymous, 1997. Bavsa-binaural beat visual analysis tool. James Peters \& Son Inc, Philadelphia, Pennsylvania. https://uazu.net/bavsa/ 
Anonymous, 2017. A creative neuroscience education website by young neuroscientists. Knowing Neurons, USA. https://knowingneurons. com/2017/ 12/21/binaural-beats\%20/

Chaieb, L., E.C. Wilpert, T.P. Reber and J. Fell, 2015. Auditory beat stimulation and its effects on cognition and mood states. Front. Psychiatry, 6: $1-9$.

George, A.G. and K. Prabavathy, 2014. A survey on different approaches used in image quality assessment. Intl. J. Comput. Sci. Network Secur., 14: 78-84.

Jirakittayakorn, N. and Y. Wongsawat, 2017. Brain responses to a 6-Hz binaural beat: Effects on general theta rhythm and frontal midline theta activity. Front. Neurosci., 11: 1-11.

Kneidinger, K.G., 2015. SiOWfa15: Science in our world, certainty and controversy. Word Press, USA. https://sites.psu.edu/siowfa15/2015/11/29/digitaldrugs-and-binaural-beats/
Mihajloski, T., J. Bohorquez and O. Ozdamar, 2014. Effects of single cycle binaural beat duration on auditory evoked potentials. Proceedings of the IEEE 36th Annual International Conference on Engineering in Medicine and Biology Society (EMBC), August 26-30, 2014, IEEE, Chicago, Illinois, USA., ISBN:978-1-4244-7929-0, pp: 4587-4590.

Nisha, S.K. and S. Kumar, 2013. Image quality assessment techniques. Intl. J. Adv. Res. Comput. Sci. Software Eng., 3: 636-640.

Padmanabhan, R., A.J. Hildreth and D. Laws, 2005. A prospective, randomised, controlled study examining binaural beat audio and pre-operative anxiety in patients undergoing general anaesthesia for day case surgery. Anaesth., 60: 874-877.

Varnan, C.S., A. Jagan, J. Kaur, D. Jyoti and D.S. Rao, 2011. Image quality assessment techniques on spatial domain. Int. J. Comput. Sci. Technol., 2: 177-184.

Wang, Z. and Q. Li, 2011. Information content weighting for perceptual image quality assessment. IEEE Trans. Image Process., 20: 1185-1198. 